\title{
Screening the nematicidal potential of indigenous medicinal plant extracts against Meloidogyne incognita under lab. and greenhouse conditions
}

\author{
Hosny Kesba ${ }^{1}$, Abdullah Abdel-Rahman ${ }^{1}$, Samy Sayed ${ }^{2^{*}}$ (D) and Al-Sayed Al-Sayed ${ }^{1}$
}

\begin{abstract}
Background: The root-knot nematode, Meloidogyne incognita, causes a high damage and yield decrease for many economic plants. The need for non-systemic effective new approaches and environmentally friendly methods for controlling the nematodes has directed research to some new and safe agrochemicals found in medicinal plants as new viable management options.

Results: In laboratory experiments, solidago and periwinkle aqueous and ethanolic extracts achieved high J2 mortality (\%) concerning different dilutions; however, aqueous extracts were more effective for mortality than ethanolic extracts. Also, there was a direct relationship between the nematicidal activity of these extracts with both concentration and time of application. Inhibition of egg hatching by Periwinkle extracts was higher than that of solidago. Moreover, the nematicidal activity of tested extracts against $\mathrm{J} 2$ decreased significantly with prolonged storage time at $+5^{\circ} \mathrm{C}$, while did not with stored frozen at $-5^{\circ} \mathrm{C}$ for 12 months. Periwinkle and solidago extracts killed the non-target organisms, i.e., rotifers and free-living nematodes. Seventy-five and $90 \%$ of total phytochemicals recovered from periwinkle and solidago, respectively were nematostatic or nematicidal to nematode viability, egg hatch in vitro, and development and reproduction in vivo despite the method of application (foliar and soil drench). The antagonistic effects of solidago were more pronounced in soil drench than periwinkle concerning their concentrations and methods of application.
\end{abstract}

Conclusion: Solidago and periwinkle plant extracts showed important sources of effective control phytochemicals against $M$. incognita.

Keywords: Meloidogyne incognita, Medicinal plant extracts, Nematicidal activity, In vitro, In vivo

\section{Background}

Botanicals can be used in in vitro and in vivo by different ways as one of the nonchemical approach strategies to manage and reduce plant-parasitic nematodes, especially in sustainable agriculture (Bridge 1996) by using their parts directly, their extracts, and compounds that possessing nematicidal activities, oilseed cakes, mature

\footnotetext{
*Correspondence: samy_mahmoud@hotmail.com

${ }^{2}$ Department of Science and Technology, University College-Ranyah, Taif University, B.O. Box 11099, Taif 21944, Saudi Arabia

Full list of author information is available at the end of the article
}

crop residues as organic amendments (Manju and Meena 2015). Some of the botanicals are already being exploited commercially in pest management and a rising trend towards organic farming (Zaidat et al. 2020).

In vitro, a lot of plant extracts showed high ovicidal and nematicidal effects on egg hatching and J2 survival of the root-knot nematode (RKN), M. incognita. Extracts from Nicotiana tabacum, Syzygium aromaticum, Piper betle, and Acorus calamus were found more effective in killing $M$. incognita, with an $\mathrm{EC}_{50}$ which was 5-10 times lower than the $\mathrm{EC}_{50}$ of the synthetic pesticides, 
chlorpyrifos, carbosulfan, and deltamethrin (Taniwiryono et al. 2009). The nematicidal effect of plant extracts could be higher than synthetic nematicides.

In vivo, (under greenhouse or field conditions) application of plant extracts reduced infection of RKN nematode and caused crop yield increase. These extracts were more effective than the nematicides used or in the same order or slightly less.

Dozens of phytochemical compounds that may be more active and eco-friendly, especially those came from medicinal and aromatic plants, e.g., serpentine, saponins, phenols, alkaloids, tannins, flavonoids, steroids, and cysteine proteinases have been reported for their antihelmintic effect against human, animal, and plant parasites (Rocha et al. 2017). The nematicidal effects of dried parts and boiled extract of Bidenspilosa were bioactive when re-evaluated on phytoparasitic nematodes after storing up to 12-18 months (Taba et al. 2012).

This study focused on the nematicidal potential of some medicinal plant extracts in the management of root-knot nematode in vitro and in vivo and their preservation on nematicidal activity, non-target organisms, and chemical composition.

\section{Methods}

\section{Nematode culture}

Pure stock culture of the RKN, M. incognita originally obtained from galled eggplant roots was established. Single egg-mass from previously identified females (Taylor et al. 1955) was used to inoculate healthy eggplants grown in $(20 \mathrm{~cm}$ diameter $)$ earthen pots filled with loamy sand soil. Three months after inoculation, plants were examined for nematode infection and reproduction. The culture was propagated and maintained on eggplant.

\section{Plant extracts preparation}

The effect of aqueous and ethanolic extracts of 13 medicinal plants was evaluated directly or after storage periods for lethal concentrations and toxicity index on survival and hatchability of $M$. incognita and non-target organisms' management under laboratory conditions (in vitro). Therefore, foliar spray and soil drench applications of solidago and periwinkle, which achieved the highest mortality percentages than the other tested plant species were carried out in the greenhouse (in vivo) on infected sunflower plants.

\section{Aqueous extracts}

Twenty-five grams of air-dried leaves of 13 medicinal plants listed in Table 1 were homogenized by grinding for 1 min using a blender to coarse particles (formation of extremely soft particles like a powder that may hamper better extraction was avoided by the
Table 1 The tested medicinal plants against Meloidogyne incognita

\begin{tabular}{lll}
\hline Family & Common name & Scientific name \\
\hline Apiaceae & Caraway & Carum carvi \\
& Coriander & Coriandrum sativum \\
Apocynaceae & Perillinkle & Anethum graveolens \\
Asteraceae & Chamomile & Catharanthus roseus \\
& Solidago & Matricaria chamomilla \\
Geraniaceae & Geranium & Solidago sp. \\
Lamiaceae & Common mint & Pelargonium graveolens \\
& Horsemint & Mentha viridis \\
& Marjoram & Mentha longifolia \\
& Rosemary & Salvia rosmarinus marjorana \\
& Sweet basil & Ocimum basilicum \\
& Thyme & Thymus vulgaris \\
\hline
\end{tabular}

solvent as described by Pandey and Tripathi 2014). Then, $1 \mathrm{~L}$ of tap water was added. The mix was transferred to a 2-L beaker and was shaken vigorously. Decoction process was done to extract watersoluble and heat-stable constituents, in which the mix was boiled for $10 \mathrm{~min}$, cooled, and filtered using filter paper. This mix was kept frozen as a stock solution (1x) until use. The stock solution was diluted by adding tap water to prepare the diluted extracts. Seven extracts dilutions $(1: 2 \times, 1: 4 \times, 1: 8 \times, 1: 16 \times, 1: 30 \times)$ were prepared by adding sufficient tap water to the stock solution till reaching the required concentrations. The 5 dilutions were equivalent, respectively, to the 5 concentrations $(12500,6250,3120,1560,780 \mathrm{mg}$ dry weight/liter (mg D.Wt./L)).

\section{Ethanolic extracts}

Five grams of the previously mentioned medicinal plants' air-dried leaves were homogenized to coarse particles using a blender, then added to $200 \mathrm{ml}$ of ethyl alcohol $96 \%$ in a 1-L beaker, shaken for $24 \mathrm{~h}$ using a shaker at room temperature, and filtered using a filter paper. A rotary evaporator was used to evaporate the solvent (ethanol) under vacuum to prepare the crude extracts, which then were dissolved in $5 \mathrm{ml}$ ethanol and added to $200 \mathrm{ml}$ tap water $+1 \mathrm{ml}$ tween 80 as a surfactant. The resulting solution was shaken and kept frozen as a stock solution $(1 \times)$. This stock solution is equivalent to a concentration of 25 mg D.Wt./L. Only 4 dilutions $(1 / 2 \times, 1 / 4 \times, 1 / 8 \times$, and $1 / 16 \times)$ were prepared by adding tap water to the stock solution till reaching the required dilutions, equivalent to $12500,6250,3120,1560 \mathrm{mg}$ D.Wt./L concentrations, respectively. 


\section{In vitro tests}

Approximately 800 newly hatched $\mathrm{J} 2$ of $M$. incognita were tested for survival after exposure to the mentioned plant extracts after $48 \mathrm{~h}$. For each treatment, 5 replicates were prepared in test tubes and kept under room temperature conditions. Juveniles in tap water only were served as a check. Mobile and immobile nematode J2s were counted under the microscope. Dead (immobile) J2s gave different strange body shapes such as $\mathrm{S}$, Curly shapes. High protozoan and metazoan activities were noticed after juveniles' death. Also, there was great degeneration 'shrinkage' starting after the stylet base and along the esophagus of the dead juveniles. Reversible effects were not expected. Mortality percent was calculated by the following formula:

$$
\text { Mortality } \%=\frac{\text { Number of dead J } 2 \text { in a treatment }}{\text { Number of totals tested J2 in the same treatment }} \times 100
$$

\section{Calculating lethal concentrations and toxicity index for $M$. incognita J2}

Data of mortality percentages (\%) in vitro were input to LDP line software to calculate probit analyses according to Finney (1971), which was used to illustrate the relation between stimulus and response in toxicological studies. The toxicity index of each plant extract was determined according to Sun (1950) using the following formula:

$$
\text { Toxicity index }=\frac{\text { LC50 of the highest effective extract }}{\text { LC50 of each extract }}
$$

\section{Egg hatching inhibition}

According to mortality rates of J2 in the last-mentioned in vitro survival test, only 2 aqueous extracts that caused the highest mortality rates were chosen to test their effect on egg hatching rates, those were solidago and periwinkle extracts. Full egg masses of $M$. incognita were teased from infected eggplant roots under the stereomicroscope. Four concentrations of the 2 extracts were tested; 500, 1000, 2000, and $4000 \mathrm{mg}$ D.Wt./L. Each replication received 5 full egg masses in a test tube, 5 replicates for each treatment, and incubated under room temperatures. The check was egg masses in tap water only. One week later, replicates were examined under the microscope to count hatched J2s. Inhibition rates were calculated according to the following formula:

$$
\text { Inhibition } \%=\frac{\text { No.of hatched J } 2 \text { in control }- \text { No.of hatched J } 2 \text { in treatment }}{\text { No.of hatched J2 in control }} \times 100
$$

\section{Effects on non-target organisms}

Concentrations of 1000 and $2000 \mathrm{mg}$ D.Wt./L of the periwinkle and solidago extracts were tested against 2 kinds of metazoans; Rotifers and free-living nematodes in vitro. Four replicates for each treatment were set and mortality percentages were calculated after $48 \mathrm{~h}$. Each replicate contained a mix of approximately 80 free-living nematodes and 100 rotifer individuals. The population of free-living nematodes was obtained from a soil sample rich in organic matter. However, rotifers were obtained from a soil sample kept at room temperature for a month to increase rotifers counts. The mixed population in water was kept as a check.

\section{Storage periods of aqueous extracts}

Samples of freshly prepared stock of each of solidago and periwinkle leave extracts were stored either under freezing at $-5{ }^{\circ} \mathrm{C}$ for 1 year, cooled for 2 weeks or 2 months at $+5{ }^{\circ} \mathrm{C}$, then they were re-evaluated for their nematicidal effect changes. The experiment procedures and mortality percentages were done as previously mentioned on M. incognita J2 in vitro.

\section{Greenhouse experiments}

Based on data obtained from the mortality in vitro tests on $M$. incognita J2s, solidago and periwinkle aqueous extracts were tested under greenhouse conditions for $M$. incognita control. Seeds of sunflower (Giza-102) plants were sown in 220 pots, each filled with $2 \mathrm{~kg}$ sandy clay soil (1:1, v:v). Two weeks later, pots were divided into two main groups which were treated as follows:

\section{Foliar spray application}

The aqueous extracts were applied as a foliar spray once. Foliar spray drift to the soil was avoided by covering it, using a tissue paper. The tested plant aqueous extracts concentrations were 500, 1000, and $2000 \mathrm{mg}$ dry leaves/L (mg D.Wt./L). Each treatment contained 5 replicates. After 2 weeks of germination, plants were inoculated with $2000 \mathrm{M}$. incognita J2s/ plant. The whole experiment was set and horticultural-maintained for 45 days after nematode inoculation. Only one factor was different for each of the 3 sub-groups, which was the time application, as follows: the first subgroup; extracts were foliar sprayed 1 week before nematode inoculation, the second sub-group; extracts were foliar sprayed simultaneously with nematode inoculation, and the third subgroup; extracts were foliar sprayed 1 week after nematode inoculation. Five replicates in each subgroup received the same treatments, except that instead of applying plant extracts, the synthetic pesticide formulation, Vydate $24 \%$ SL (oxamyl) was foliar sprayed as a standard chemical nematicide $(3 \mathrm{ml} / \mathrm{L})$. Another 5 replicates were inoculated with nematode only and kept as a check. 


\section{Soil drench application}

The aqueous extracts were applied as a soil drench once (100 ml/plant). The tested plant aqueous extracts (solidago and periwinkle dry leaves extracts) concentrations were 500, 1000, and $2000 \mathrm{mg}$ dry leaves/L (mg D.Wt./L). This group contained 110 pots, each treatment contained 5 replicates. Inoculum level was $2000 \mathrm{~J} 2$ of $M$. incognita after 2 weeks of germination. One factor was different for each of the 3 sub-groups, which was the time of extracts application as follows: the first subgroup; $100 \mathrm{ml}$ of extracts solution were applied as a soil drench for each pot 1 week before nematode inoculation, the second sub-group; $100 \mathrm{ml}$ of extracts were applied simultaneously with nematode inoculation, and the third sub-group: $100 \mathrm{ml}$ of extracts were applied 1 week after nematode inoculation. Five replicates in each subgroup were received the same treatments except that, instead of applying plant extracts, the synthetic pesticide formulation, Vydate $24 \% \mathrm{SL}$, was soil drenched as a standard chemical nematicide $(0.1 \mathrm{ml} / \mathrm{L})$. Another 5 replicates were inoculated by nematode only and kept as a check.

\section{Nematode assay}

Upon harvest, each pot was soaked in a plastic bucket filled with water until the root system could be easily separated. Each root system was weighed and stored in $5 \%$ formaldehyde in plastic jars. The soil suspension was quite stirred and then poured through a series of 60 and 325 mesh screens (Hooper et al. 2005). The bottom sieve was then poured onto a modified Baermann set and collected after $48 \mathrm{~h}$. Hawksley counting slide was used to calculate the number of $\mathrm{J} 2 \mathrm{~s}$ in $1 \mathrm{ml}$ of the suspension and then referred to the whole volume. The numbers of galls and egg-masses were counted directly on the root system of each replicate and the mean of each treatment was calculated and later the eggs were extracted (Boneti and Ferraz 1981). For calculating eggs per egg mass, 10 full egg masses from each replicate were chosen, gelatin matrix was dissolved using sodium hypochlorite ( $\mathrm{NaOCl}$ ) according to (Hussey and Barker 1973), and eggs were counted in $1 \mathrm{ml}$ volume under the microscope. The final population (eggs + soil population) plotted in the formula $R F=P f / P i$, where $R F$ is the reproduction factor, Pf the final population, and Pi the initial population (Oostenbrink 1966).

\section{GC/MS/MS analysis}

\section{Sample preparation}

Five grams of grinded dried leaves of each plant (periwinkle and solidago) were added to $100 \mathrm{ml}$ deionized water in a $250-\mathrm{ml}$ flask. The decoction process was done as previously mentioned. The extract was filtered, using filter paper, centrifuged at $9000 \mathrm{rpm}$ for $5 \mathrm{~min}$ to exclude any impurities, then it was lyophilized (freezedried).

\section{Chromatographic analysis}

Produced powder from the last step was analyzed using gas chromatography/mass spectrometry and gas chromatography/tandem mass spectrometry (GC/MS/MS). The analysis was carried out using a GC (Agilent Technologies 7890A) interfaced with a mass selective detector (MSD, Agilent 7000) equipped with a polar Agilent HP-5ms (5\%-phenyl methyl polysiloxane) capillary column $(30 \mathrm{~m} \times 0.25 \mathrm{~mm}$ i. d. and $0.25 \mu \mathrm{m}$ film thickness). The carrier gas was helium with a linear velocity of $1 \mathrm{ml} / \mathrm{min}$. The injector and detector temperatures were 200 and $250{ }^{\circ} \mathrm{C}$, respectively. The volume injected $1 \mu \mathrm{l}$ of the sample. The MS operating parameters were as follows: ionization potential $70 \mathrm{eV}$, interface temperature $250{ }^{\circ} \mathrm{C}$, and acquisition mass range $50-800$.

The identification of components was based on a comparison of their mass spectra and retention time with those of the authentic compounds and by computer matching with NIST and WILEY library as well as by comparison of the fragmentation pattern of the mass spectral data with those reported in the literature (Dong et al. 2014).

\section{Statistical analysis}

Data were statistically analyzed one-way ANOVA according to the SPSS software package version 23. The differences between means were tested using Duncan's multiple tests at the $5 \%$ significance level.

\section{Results}

Effect of aqueous extracts on $\mathbf{J} 2$ mortality

Dry leaf powder extracts of 13 medicinal plant species were tested in a laboratory assay on M. incognita J2s' mortality with 5 dilutions of each. In general, after $48 \mathrm{~h}$ of exposure, all extracts used had nematicidal action against $M$. incognita J2 depending on the plant species and rate of the aqueous extract dilution (Table 2). The percent of mortality decreased by increasing extracts dilutions, except that of solidago and periwinkle dry leaf extracts. However, the first 2 dilutions $1: 2 \times$ and 1:4× were highly toxic in all extracts achieving $100 \%$ mortality. Leaf extracts of solidago and periwinkle displayed the highest toxicity in (1:16x and 1:30x dilutions) than the rest of medicinal extracts, although, the percentage of mortality decreased down to almost $70 \%$ at $(1: 30 \times$ dilution). A considerable decrease in $\mathrm{J} 2$ mortality appeared by (1:16x dilution), less than $50 \%$ of J2s were killed by Common mint, horsemint, geranium, and dill extracts. The least percentages of mortality at (1:30x dilution) were recorded by extracts of marjoram, chamomile, and geranium, which were almost similar to the acceptable 
Table 2 Mortality percentages of M. incognita J2s as influenced by dry leaves aqueous extracts of selected medicinal plants at different dilutions

\begin{tabular}{|c|c|c|c|c|c|c|c|c|c|}
\hline \multirow{4}{*}{$\begin{array}{l}\text { Aqueous extract } \\
(1 \times \text { stock } \\
\text { solution }=25,000 \\
\text { mg D.Wt./L) }\end{array}$} & \multicolumn{5}{|c|}{ 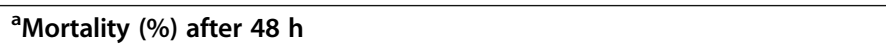 } & \multirow{4}{*}{$\begin{array}{l}\text { Accumulative } \\
\text { mortality }\end{array}$} & \multirow{4}{*}{$\begin{array}{l}\text { b'Toxicity } \\
\text { index }\end{array}$} & \multirow{3}{*}{\multicolumn{2}{|c|}{$\begin{array}{l}\text { Lethal } \\
\text { Concentrations } \\
(\mathrm{mg} \mathrm{D.Wt./L)c}\end{array}$}} \\
\hline & \multicolumn{5}{|c|}{ Concentration with $\mathrm{X}$ dilution and equivalent $\mathrm{mg}$ dry weight/L } & & & & \\
\hline & \multirow{2}{*}{$\begin{array}{l}1: 2 \times \\
(12500 \mathrm{mg} / \mathrm{L})\end{array}$} & \multirow{2}{*}{$\begin{array}{l}1 /: 4 \times \\
(6250 \mathrm{mg} / \mathrm{L})\end{array}$} & \multirow{2}{*}{$\begin{array}{l}1: 8 \times \\
(3120 \mathrm{mg} / \mathrm{L})\end{array}$} & \multirow{2}{*}{$\begin{array}{l}1: 16 \times \\
(1560 \mathrm{mg} / \mathrm{L})\end{array}$} & \multirow{2}{*}{$\begin{array}{l}1: 30 \times \\
(780 \mathrm{mg} / \mathrm{L})\end{array}$} & & & & \\
\hline & & & & & & & & $\mathrm{LC}_{50}$ & $\mathrm{LC}_{90}$ \\
\hline Basil & 100 & 100 & 88 & 62 & 30 & 380 & 0.42 & 1320 & 3177 \\
\hline Caraway & 100 & 100 & 95 & 81 & 15 & 391 & 0.44 & 1261 & 2199 \\
\hline Chamomile & 100 & 100 & 93 & 85 & 9 & 387 & 0.41 & 1340 & 2263 \\
\hline Common mint & 100 & 100 & 82 & 38 & 17 & 336 & 0.29 & 1884 & 4322 \\
\hline Coriander & 100 & 100 & 85 & 60 & 12 & 357 & 0.31 & 1759 & 3140 \\
\hline Dill & 100 & 100 & 61 & 36 & 10 & 307 & 0.22 & 2554 & 6232 \\
\hline Geranium & 100 & 100 & 70 & 37 & 8 & 316 & 0.24 & 2266 & 4779 \\
\hline Horsemint & 100 & 98 & 63 & 49 & 13 & 323 & 0.28 & 1996 & 5091 \\
\hline Marjoram & 100 & 100 & 100 & 91 & 5 & 396 & 0.51 & 1086 & 1712 \\
\hline Periwinkle & 100 & 100 & 100 & 100 & 73 & 473 & 0.75 & 737 & 1101 \\
\hline Rosemary & 100 & 100 & 69 & 60 & 36 & 365 & 0.40 & 1372 & 10774 \\
\hline Solidago & 100 & 100 & 100 & 98 & 72 & 470 & 1.0 & 549 & 1038 \\
\hline Thyme & 100 & 100 & 69 & 54 & 37 & 361 & 0.35 & 1572 & 11572 \\
\hline Check (tap water) & 9 & 9 & 5 & 7 & 8 & & - & - & - \\
\hline
\end{tabular}

natural death percentage in the check (without treatment).

The relative toxicity index was measured by calculating and comparing each J2's mortality relative to the maximum percentage of mortality. The accumulative percentages of mortality were calculated as well and were the highest in periwinkle followed by solidago and the least was found in Fros dill. The toxicity index, as well as the accumulative percentage of mortality, followed the same trend where the highest toxicity index was gained by solidago extract, followed by periwinkle and marjoram, respectively. While dill recorded the lowest relative toxicity value.

Concerning the lethal concentration needed to achieve $\mathrm{LC}_{50}$, it was found that solidago recorded the lowest lethal concentration that achieved such criteria and it was almost $1 / 2: 1 / 3$ of most extracts concentrations, followed by periwinkle. Geranium and dill needed four times concentrations as much as solidago to attain $\mathrm{LC}_{50}$. $\mathrm{LC}_{90}$ was found to be achieved by a concentration of almost $1 \mathrm{~g}$ D.Wt./L in solidago extract. The lowest lethal concentration for $\mathrm{LC}_{90}$ was raised to 5 times in horsemint, 10 and 11 times in rosemary and thyme extracts, respectively. Solidago and periwinkle extracts recorded almost the same lethal concentration required to achieve $\mathrm{LC}_{90}$.

\section{Effect of ethanolic extracts on $\mathbf{J} 2$ mortality}

The ethanolic extracts of the previously mentioned medicinal plant species were tested on M. incognita J2s mortality at 3 dilutions. After $48 \mathrm{~h}$ exposure, the ethanolic dry leaf extracts of all medicinal species were found lethal to $M$. incognita J2s, regardless of the rate of dilution, although the mortality percentages differed according to plant species extract and dilution (Table 3). There was direct proportional relation to a great extent between mortality and dilution. Considerable high mortality rates were noticed at 1:2× dilution in most cases than $1: 4 \times$ or $1: 8 \times$ dilutions. Coriander, geranium, solidago, marjoram, basil, and periwinkle extracts achieved higher mortality in $1: 4 \times$ dilution than that of $1: 2 \times$ or $1: 8 \times$ dilutions. The general decrease in $\mathrm{J} 2$ mortality was recorded in 1:8x dilution, when compared with the others. The accumulative mortality percentages of geranium, marjoram, and solidago were the highest meanwhile; horsemint, chamomile, and dill were the lowest. However, the toxicity index of solidago extract was in the lead of all extracts.

From the results, it seems that the aqueous extracts of dry leaves of medicinal species were much more efficient in being nematoxic or nematicidal to $M$. incognita J2s than ethanolic extracts in all dilutions and that was reflected positively on the least lethal concentrations required for $\mathrm{LC}_{50}$ and $\mathrm{LC}_{90}$. 
Table 3 Mortality percentages of M. incognita J2 as influenced by dry leaves ethanolic extracts of selected medicinal plants at different dilutions

\begin{tabular}{|c|c|c|c|c|c|c|c|}
\hline \multirow{2}{*}{$\begin{array}{l}\text { Ethanolic extract } \\
\text { (X stock solution } \\
=25,000 \mathrm{mg} \\
\text { D.Wt./L) }\end{array}$} & \multicolumn{3}{|l|}{${ }^{a}$ Mortality (\%) } & \multirow[t]{2}{*}{$\begin{array}{l}\text { Accumulative } \\
\text { mortality }\end{array}$} & \multirow[t]{2}{*}{$\begin{array}{l}\text { boxicity } \\
\text { index }\end{array}$} & \multicolumn{2}{|c|}{$\begin{array}{l}\text { Lethal } \\
\text { concentrations (mg } \\
\text { D.Wt./L) }\end{array}$} \\
\hline & $1: 2 \times(12,500 \mathrm{mg} \mathrm{DW} / \mathrm{L})$ & $1: 4 \times(6250 \mathrm{mg} \mathrm{DW} / \mathrm{L})$ & $1: 8 \times(3120 \mathrm{mg} \mathrm{DW} / \mathrm{L})$ & & & $\mathrm{LC}_{50}$ & $\mathrm{LC}_{90}$ \\
\hline Basil & 55 & 74 & 51 & 180 & 0.5 & 4465 & 67721 \\
\hline Caraway & 86 & 39 & 22 & 147 & 0.3 & 7118 & 16549 \\
\hline Chamomile & 39 & 31 & 11 & 80 & 0.1 & 17799 & 71141 \\
\hline Common mint & 71 & 63 & 17 & 151 & 0.3 & 7111 & 20271 \\
\hline Coriander & 61 & 84 & 21 & 165 & 0.4 & 5929 & 16457 \\
\hline Dill & 65 & 8 & 7 & 80 & 0.2 & 11376 & 19052 \\
\hline Geranium & 83 & 88 & 57 & 229 & 0.8 & 2597 & 13139 \\
\hline Horsemint & 57 & 17 & 10 & 84 & 0.2 & 12718 & 41034 \\
\hline Marjoram & 65 & 94 & 61 & 221 & 0.7 & 3015 & 13889 \\
\hline Periwinkle & 32 & 55 & 51 & 138 & 0.2 & 10410 & 149504 \\
\hline Rosemary & 61 & 35 & 20 & 115 & 0.2 & 10623 & 39146 \\
\hline Solidago & 49 & 94 & 67 & 210 & 1.0 & 2085 & 14702 \\
\hline Thyme & 100 & 54 & 30 & 184 & 0.4 & 5533 & 13071 \\
\hline Check (tap water) & 27 & 8 & 9 & & & & \\
\hline
\end{tabular}

${ }^{a}$ Mortality $\%=\frac{\text { Number of dead } \mathrm{J} 2 \text { in a treatment }}{\text { Number of totals tested } \mathrm{J} 2 \text { in the same treatment }}$

${ }^{\mathrm{b}}$ Toxicity index $=$ LC50 of the highest effective extract

${ }^{\mathrm{C}} \mathrm{mg}$ D.Wt./L= milligram dry leaves per liter

\section{Effect of storage aqueous extracts against J2}

Results of the previous in vitro experiment verified that extracts of solidago and periwinkle recorded the ultimate percentages of $\mathrm{J} 2$ mortality amongst all the tested aqueous extracts. So, the effect of storage conditions and temperature on extracts stability and activity and in turn, their immobilization activity was studied (Table 4). The storage time affected the extract's capability on mortality. The nematoxic effects of extracts were match able to those of expected fresh after 14 days storage in the fridge at $+5{ }^{\circ} \mathrm{C}$, but when the storage period was prolonged up to 60 days, the stability of the phytochemicals was drastically affected, which in turn minimized mortality in solidago aqueous extract treatments. That minimization was more pronounced at $1000 \mathrm{mg} \mathrm{D.Wt}$./ $\mathrm{L}$ concentration. The activity of periwinkle extract lower concentration was less effective than the higher one. The activity of extracts differed after 12 months of freezing conditions at $-5{ }^{\circ} \mathrm{C}$. Periwinkle activity was stable achieving $92 \%$ mortality at $1000 \mathrm{mg}$ D.Wt./L and heightened up to $100 \%$ at the higher concentration. The opposite was found to be the case in solidago extract lower concentration (78\% mortality). The higher concentration was highly effective as much as expected fresh or 14 days cooled storage. It seems that $\mathrm{J} 2 \mathrm{~s}$ mortality retrogrades proportionally with the time of extract storage.

Table 4 Effect of storage period and temperature on extracts nematicidal activity against $M$. incognita $\mathrm{J} 2$ in vitro

\begin{tabular}{|c|c|c|c|c|c|}
\hline \multirow{2}{*}{$\begin{array}{l}\text { Aqueous } \\
\text { extract }\end{array}$} & \multirow{2}{*}{$\begin{array}{l}\text { Conc. } \\
\text { (mg } \\
\text { D.Wt./ } \\
\text { L) }^{\mathrm{a}}\end{array}$} & \multirow{2}{*}{$\begin{array}{l}\text { Expected } \\
\text { fresh } \\
\text { extracts } \\
\text { Mortality } \\
\% \text { (LDP } \\
\text { line) }\end{array}$} & \multicolumn{3}{|l|}{${ }^{\mathrm{b}}$ Mortality (\%) } \\
\hline & & & Frozen extracts $\left(-5^{\circ} \mathrm{C}\right)$ for 1 year & Cooled extracts $\left(5^{\circ} \mathrm{C}\right)$ for 14 days & Cooled extracts $\left(5^{\circ} \mathrm{C}\right)$ for 60 days \\
\hline \multirow[t]{2}{*}{ Periwinkle } & 1000 & Approx. 90 & 92 & 100 & 71 \\
\hline & 2000 & $>95$ & 100 & 100 & 92 \\
\hline \multirow[t]{2}{*}{ Solidago } & 1000 & Approx. 90 & 78 & 95 & 17 \\
\hline & 2000 & $>99$ & 98 & 100 & 33 \\
\hline Check & - & 7 & 9 & 5 & 2 \\
\hline
\end{tabular}

${ }^{\mathrm{a}} \mathrm{mg}$ D.Wt./L= milligram dry leaves per liter.

${ }^{\mathrm{b}}$ Mortality $\%=\frac{\text { Number of dead } \mathrm{J} 2 \text { in a treatment }}{\text { Number of totals tested } \mathrm{J} 2 \text { in the same treatment }}$ 
The efficacy of treatment was improved by doubling the concentration but not with the time of storage.

\section{Effect of aqueous extracts on egg hatching}

Solidago and periwinkle aqueous extracts which were found to be the most efficient on M. incognita J2s mortality were selected to study their effect on hatching of egg masses at 3 concentrations after 7 days of exposure. Significant inhibitory effects on the numbers of hatched eggs when compared with the check were observed (Fig. 1). Also, significant differences were found between and within treatments. Periwinkle extract was significantly efficient in reducing the number of hatched eggs at all concentrations. Non-significant differences were found between the lowest and middle concentrations of periwinkle. There was a significant positive correlation between the concentration of each aqueous extract and the rate of inhibition. The highest rate of inhibition was recorded at periwinkle (98.9\%), followed by solidago (87.5\%) with the highest concentration (1000 mg D.wt./ $\mathrm{L})$. The lowest inhibitory effects were found in the case of the lowest concentration of solidago extract (23.4\%).

\section{Effect of periwinkle and solidago aqueous extracts on non-target organisms}

A further in vitro experiment was conducted to study the effect of solidago and periwinkle dry leaf aqueous extracts at 2 concentrations (1000, $2000 \mathrm{mg} \mathrm{D.Wt} . / \mathrm{L})$ on the free-living nematode genera and rotifers, which were found co-inhabiting the soil with the root-knot nematodes. The recessive effects on both microorganisms were observed regardless of the type of plant extract as well as concentration; however, solidago extract was more efficient than periwinkle were obvious in Fig. 2. Effects on rotifers were more retrograded than free-living nematodes. Mortality of rotifers after $48 \mathrm{~h}$ treatment was consistent in periwinkle leaf extract at the two used concentrations, which achieved more than $50 \%$ mortality. It is interesting to notice that percentage of mortality in solidago treatments was directly correlated with concentration, 66.5 at the lower and 84.7 at the higher. On the other hand, solidago aqueous extract interpreted almost similar mortality percentages at the lower and higher concentrations on free-living nematodes. Periwinkle extract at $1000 \mathrm{mg}$ D.wt./L recorded mortality values on free-living nematodes $10 \%$ less than its higher concentration which was close to solidago extract concentrations.

\section{Chemical content of solidago and periwinkle dry leaves}

Quantitative and qualitative analysis of phytochemicals in dry leaves of periwinkle and solidago was carried out by GC-MS-MS. The leaf extract manifested four main phytochemical classes. Flavonoids, terpenoids, phenolics,

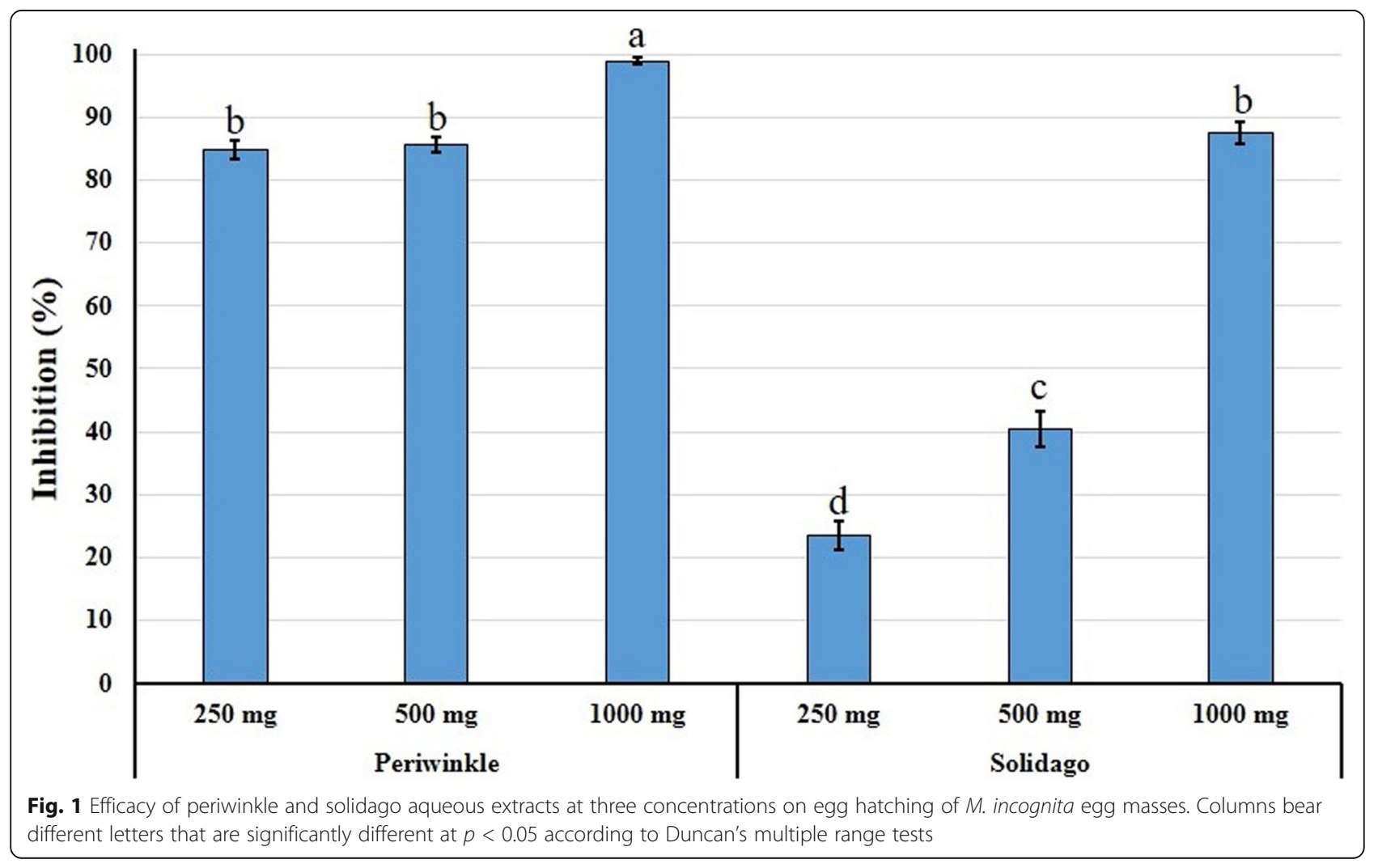




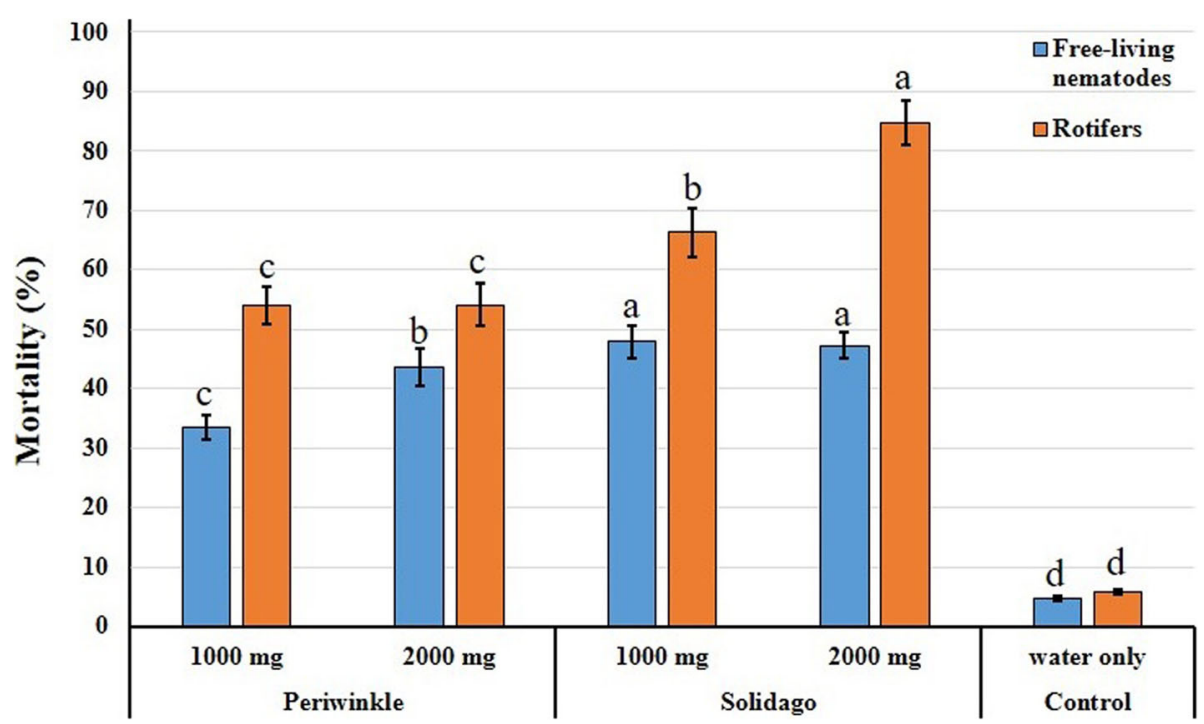

Fig. 2 Efficacy of periwinkle and solidago aqueous extracts on the mortality of free-living nematodes and rotifers after $48 \mathrm{~h}$ in vitro. Columns of the same organism bear different letters are significantly different at $p<0.05$ according to Duncan's multiple range tests

and coumarins were highly present with different concentrations. Flavonoids were the most dominant in all the extracts, followed by the terpenoids, phenolics, and coumarins in the solidago leaf extract. Phenolic compounds were the maximum class found in periwinkle leaves (59.2\%), followed by flavonoids (19.7\%) and coumarins (5.2\%). The minimum was piperazines (3.9\%), glycosides (2.6\%), and phytosterols (2.4\%) in solidago leaves, respectively. Meanwhile, the lowest ratios were organic alcohol (4\%), fatty acids (4.1\%), alkaloids (3\%), and sesquiterpenoids (3\%) in periwinkle leaves. There were correspondingly prohibiting effects of the main chemical classes and the ratios on nematode activity, egg inhibition and development, and reproductively.

\section{Effect of periwinkle and solidago aqueous extracts on RKN infecting sunflower}

Potentials of periwinkle, solidago dry leaves aqueous extracts under 3 intervals (pre, with, and post-inoculation), 2 methods of application (foliar spray, soil drench) with $100 \mathrm{ml}$ of each of the concentrations (500, 1000, 2000 mg D.Wt./L), and the comparable nematicide Vydate ${ }^{\circ}$ $24 \%$ SL on $M$. incognita in greenhouse experiment was detected and illustrated in Tables 5 and 6.

\section{Foliar spray application}

Apropos of pre-inoculation, periwinkle, and solidago extracts significantly suppressed the numbers of formed galls, egg masses, and eggs/egg mass. Except for periwinkle extracts, the numbers of eggs exceeded the nematode check and consequently reflected on nematode reproduction, which was more or less the nematode check. Solidago treatment concentrations performed significant impressive reductions in all nematode criteria and exhibited smashup in nematode final population and buildup. Obvious direct proportional effects were noticed among solidago concentration. Very few eggs were laid in the highest sprayed concentration $(2000 \mathrm{mg}$ D.Wt./L) achieving the lowest buildup (Table 5).

As for inoculation abreast with foliage spray, all treatments concentration imposed significant smashing reductions on all nematode criteria either intra- or interspecific treatments except the foliar sprays of solidago at 500, $1000 \mathrm{mg} \mathrm{D.Wt./L}$ at the number of deposited eggs and buildup, where the nematode was able to fold only once with non-significant differences with the check. Periwinkle concentrations were the most invincible where the least buildup rates were performed.

The post-inoculation treatment followed the same trend with the abreast one, all treatments were significantly effective in reducing numbers of galls, egg masses, final population, and the subsequent buildup and egg production when compared with the check. Solidago and periwinkle at 1000, $2000 \mathrm{mg}$ D.Wt./L outmatched Vydate $24 \%$ SL.

Concerning the foliar spray treatment, Vydate ${ }^{\bullet}$ at all intervals, the nematode galls, egg masses, and fecundity were sharply declined. Values of buildup were eliminated with significant differences where the nematode was not able to fold even once in pre- and post-inoculations.

\section{Soil drench application}

Efficacies of the aqueous extracts of periwinkle and solidago on $M$. incognita at different intervals and same concentrations as previously mentioned and treated as a soil drench to sunflower plants are given in Table 6. It 
Table 5 Effect of foliar spray of periwinkle and solidago aqueous extracts at different concentrations and application time on $M$. incognita infecting sunflower plants

\begin{tabular}{|c|c|c|c|c|c|c|}
\hline Plant extract & Concentration (mg D.Wt/L) & Galls/root & Egg masses/root & Eggs/mass & Final population $(\mathrm{Pf})$ & $\mathrm{Rf}^{* *}$ \\
\hline \multicolumn{7}{|l|}{ Pre- inoculation } \\
\hline \multirow[t]{3}{*}{ Periwinkle } & 500 & $18 \mathrm{de}$ & $43 \mathrm{~cd}$ & $116 \mathrm{a}$ & $4959 d$ & $2.5 \mathrm{c}$ \\
\hline & 1000 & $42 \mathrm{c}$ & $104 a$ & $108 \mathrm{~b}$ & 11,232 a & $5.6 \mathrm{a}$ \\
\hline & 2000 & $89 a$ & $114 a$ & $59 d$ & $6726 c$ & $3.4 \mathrm{c}$ \\
\hline \multirow[t]{3}{*}{ Solidago } & 500 & $38 c$ & $79 \mathrm{~b}$ & $38 \mathrm{f}$ & 3002 e & $1.5 e$ \\
\hline & 1000 & $16 \mathrm{e}$ & $81 \mathrm{~b}$ & 43 e & 3483 e & $1.7 e$ \\
\hline & 2000 & $21 d$ & $28 d$ & $10 \mathrm{~h}$ & $280 \mathrm{~g}$ & $0.1 \mathrm{~g}$ \\
\hline Vydate $^{\oplus} 24 \%$ SL & $3 \mathrm{ml} / \mathrm{L}$ & $22 \mathrm{~d}$ & $58 c$ & $30 \mathrm{~g}$ & $1725 f$ & $0.9 \mathrm{f}$ \\
\hline Check & Water only & $69 \mathrm{~b}$ & $115 a$ & $66 c$ & $7590 \mathrm{~b}$ & $3.8 \mathrm{~b}$ \\
\hline \multicolumn{7}{|l|}{ With inoculation } \\
\hline \multirow[t]{3}{*}{ Periwinkle } & 500 & $14 d$ & $15 \mathrm{c}$ & $25 \mathrm{~g}$ & $375 c$ & $0.2 \mathrm{c}$ \\
\hline & 1000 & $44 \mathrm{~b}$ & 39 e & $27 f$ & $1053 \mathrm{~b}$ & $0.5 \mathrm{~b}$ \\
\hline & 2000 & $18 d$ & $17 \mathrm{c}$ & $15 \mathrm{~h}$ & $255 c$ & $0.1 \mathrm{c}$ \\
\hline \multirow[t]{3}{*}{ Solidago } & 500 & $17 d$ & $18 \mathrm{c}$ & $107 b$ & 1926 a & $1.0 \mathrm{a}$ \\
\hline & 1000 & $15 d$ & $18 \mathrm{c}$ & 113 a & $2072 \mathrm{a}$ & $1.0 \mathrm{a}$ \\
\hline & 2000 & $22 c$ & $9 d$ & $104 \mathrm{c}$ & $901 \mathrm{~b}$ & $0.5 \mathrm{~b}$ \\
\hline Vydate $^{\circledast} 24 \% \mathrm{SL}$ & $3 \mathrm{ml} / \mathrm{L}$ & $66 \mathrm{a}$ & $27 \mathrm{~b}$ & $76 d$ & 2077 a & $1.0 \mathrm{a}$ \\
\hline Check & water only & 8 e & $26 \mathrm{~b}$ & $70 \mathrm{e}$ & $1820 \mathrm{a}$ & $0.9 \mathrm{a}$ \\
\hline \multicolumn{7}{|l|}{ Post-inoculation } \\
\hline \multirow[t]{3}{*}{ Periwinkle } & 500 & $38 a$ & $55 \mathrm{a}$ & $55 f$ & 3025 c & $1.5 \mathrm{c}$ \\
\hline & 1000 & $7 c$ & $13 \mathrm{e}$ & $98 c$ & $1274 \mathrm{~d}$ & $0.6 \mathrm{c}$ \\
\hline & 2000 & $9 c$ & $17 d$ & $78 d$ & $1326 d$ & $0.7 \mathrm{c}$ \\
\hline \multirow[t]{3}{*}{ Solidago } & 500 & $13 b$ & $31 \mathrm{~b}$ & $171 \mathrm{~b}$ & $5301 \mathrm{~b}$ & $2.7 \mathrm{~b}$ \\
\hline & 1000 & $2 d$ & $3 f$ & $\mathrm{Oh}$ & $0 \mathrm{e}$ & $0.0 \mathrm{e}$ \\
\hline & 2000 & $14 \mathrm{~b}$ & 16 de & $56 \mathrm{e}$ & $896 d$ & $0.4 \mathrm{c}$ \\
\hline Vydate $^{\circledast} 24 \%$ SL & $3 \mathrm{ml} / \mathrm{L}$ & $8 c$ & 15 de & $12 \mathrm{~g}$ & $180 \mathrm{e}$ & $0.1 e$ \\
\hline Check & Water only & $6 c$ & $26 c$ & $428 \mathrm{a}$ & 11,128 a & $5.6 a$ \\
\hline
\end{tabular}

Means in the same column followed by the different letter(s) are significantly different at $p<0.05$ according to Duncan's multiple range tests

* mg D Wt./L = milligram dry leaves/liter of water

${ }^{* *} \mathrm{Rf}($ reproduction factor $)=\mathrm{Pf}($ final population)/Pi (inatial population)

contended in general that soil drench applications were more effective in reducing nematode criteria than foliar spray as measured by gall formation, egg masses fecundity, and buildup. Referring to the used concentrations, most if not all extracts concentrations were highly suppressive for nematode parameters. Solidago extracts surpassed to great extent periwinkle extracts at all intervals and concentrations. Controvert effects were noticeable in periwinkle extracts at 500, $2000 \mathrm{mg} \mathrm{D.Wt}$./L at preand post-inoculation intervals, where the nematode was able to fold more than once as compared with the untreated inoculated check. The detersive effects of Vydate were more malignant when treated as soil drench than foliar spray and in particular when treated, with inoculation, no J2s were able to invade the roots.

\section{Discussion}

GC/MS/MS analysis indicated the presence of phytochemicals belonging to the following classes: phenols, flavonoids, triterpenoids, coumarins, alkaloids, and glycosides. groups with different concentrations. Solidago and periwinkle extracts were in the lead of all the 13 tested extracts in achieving the highest percentages of mortality. Ethanol extracts were effective in increasing mortality to $M$. incognita J2s but not as much as aqueous extracts. This may be due to the polarity of the solvent; the polarity of water is higher than that of ethanol. Consequently, higher antioxidants and phenols were extracted using water. $\mathrm{Ng}$ et al. (2020) reported that polar solvents could extract higher amounts of antioxidants and phenolic compounds, which increase the radical 
Table 6 Effect of soil drench of periwinkle and solidago aqueous extracts at different concentrations and application time on M. incognita infecting sunflower plants

\begin{tabular}{|c|c|c|c|c|c|c|}
\hline Plant extract & Conc. (mg D.Wt/L) & Galls/root & Egg masses/root & Eggs/mass & Final population (Pf) & $R f^{* *}$ \\
\hline \multicolumn{7}{|l|}{ Pre-inoculation } \\
\hline \multirow[t]{3}{*}{ Periwinkle } & 500 & $63 c$ & $176 a$ & $38 \mathrm{~b}$ & 6698 a & $3.3 \mathrm{a}$ \\
\hline & 1000 & $64 c$ & $91 \mathrm{c}$ & $39 a$ & $3549 b$ & $1.8 \mathrm{~b}$ \\
\hline & 2000 & $149 a$ & 171 a & $15 \mathrm{~g}$ & $2565 d$ & $1.3 d$ \\
\hline \multirow[t]{3}{*}{ Solidago } & 500 & $36 \mathrm{e}$ & $93 c$ & $26 \mathrm{e}$ & $2418 d$ & $1.2 \mathrm{e}$ \\
\hline & 1000 & $72 b$ & $89 c$ & $20 \mathrm{f}$ & $1770 \mathrm{f}$ & $0.9 \mathrm{f}$ \\
\hline & 2000 & $43 d$ & $69 d$ & $32 c$ & 2208 e & $1.1 \mathrm{e}$ \\
\hline Vydate $^{\circledast} 24 \%$ SL & $0.1 \mathrm{ml} / \mathrm{L}$ & $45 d$ & $17 \mathrm{e}$ & $8 \mathrm{~h}$ & $136 \mathrm{~g}$ & $0.1 \mathrm{~g}$ \\
\hline Check & Water only & $76 b$ & $111 \mathrm{~b}$ & $30 d$ & $3330 \mathrm{c}$ & $1.7 \mathrm{C}$ \\
\hline \multicolumn{7}{|l|}{ With inoculation } \\
\hline \multirow[t]{3}{*}{ Periwinkle } & 500 & $11 \mathrm{c}$ & $33 a$ & $89 c$ & 2959 a & $1.5 \mathrm{a}$ \\
\hline & 1000 & $10 \mathrm{c}$ & $23 b$ & $74 d$ & $1665 b$ & $0.8 \mathrm{~b}$ \\
\hline & 2000 & $9 c$ & $14 \mathrm{c}$ & $92 \mathrm{~b}$ & $1288 \mathrm{~b}$ & $0.6 \mathrm{~b}$ \\
\hline \multirow[t]{3}{*}{ Solidago } & 500 & $11 b c$ & $17 \mathrm{c}$ & $179 a$ & 2998 a & $1.5 \mathrm{a}$ \\
\hline & 1000 & $16 \mathrm{a}$ & $28 \mathrm{~b}$ & $63 f$ & $1733 b$ & $0.9 \mathrm{~b}$ \\
\hline & 2000 & $14 a b$ & $15 c$ & $29 \mathrm{~g}$ & $421 \mathrm{c}$ & $0.2 \mathrm{c}$ \\
\hline Vydate $^{\oplus} 24 \%$ SL & $0.1 \mathrm{ml} / \mathrm{L}$ & $1 d$ & $0 d$ & $\mathrm{Oh}$ & $0 \mathrm{c}$ & $0.0 \mathrm{c}$ \\
\hline Check & Water only & $10 \mathrm{c}$ & $25 \mathrm{~b}$ & $71 \mathrm{e}$ & $1775 b$ & $0.9 \mathrm{~b}$ \\
\hline \multicolumn{7}{|l|}{ Post-inoculation } \\
\hline \multirow[t]{3}{*}{ Periwinkle } & 500 & $52 \mathrm{~b}$ & $49 c$ & $87 c$ & $4263 c$ & $2.1 \mathrm{C}$ \\
\hline & 1000 & $52 \mathrm{~b}$ & $40 d$ & 75 e & $2963 d$ & $1.5 \mathrm{~d}$ \\
\hline & 2000 & $65 a$ & $74 \mathrm{a}$ & $88 \mathrm{~b}$ & $6490 \mathrm{a}$ & $3.2 \mathrm{a}$ \\
\hline \multirow[t]{3}{*}{ Solidago } & 500 & $53 \mathrm{~b}$ & 33 e & $68 f$ & $2210 \mathrm{e}$ & $1.1 \mathrm{e}$ \\
\hline & 1000 & $65 a$ & $62 b$ & $50 \mathrm{~h}$ & $3100 d$ & $1.6 d$ \\
\hline & 2000 & $70 \mathrm{a}$ & $41 \mathrm{~d}$ & $75 d$ & $3038 d$ & $1.5 \mathrm{~d}$ \\
\hline Vydate $^{\circledast} 24 \%$ SL & $0.1 \mathrm{ml} / \mathrm{L}$ & $11 \mathrm{c}$ & $16 f$ & $65 \mathrm{~g}$ & $1056 \mathrm{f}$ & $0.5 \mathrm{f}$ \\
\hline Check & Water only & $66 a$ & $52 c$ & $99 \mathrm{a}$ & $5148 b$ & $2.6 \mathrm{~b}$ \\
\hline
\end{tabular}

Means in the same column followed by the different letter(s) are significantly different at $p<0.05$ according to Duncan's multiple range tests

${ }^{* *} \mathrm{Rf}($ reproduction factor $)=\mathrm{Pf}($ final population $) / \mathrm{Pi}$ (inatial population)

scavenging activity of the extracts. Neeraj et al. (2017) reported that alcoholic extracts showed a high activity in immobilization of $M$. incognita J2s and egg hatching inhibition in vitro. That may be because they used high concentrations.

The nature of medicinal plant structure and their derivatives have been discussed extensively but the mode of action of most nematicidal phytochemicals is still ambiguous. Periwinkle achieved more inhibitory effects on egg hatchability than solidago extract. That inhibition was proportionally correlated with concentration increase. It is well known that periwinkle extracts are rich in alkaloids. Extracts that contain alkaloids were found to have ovicidal property against Meloidogyne eggs (Adegbite 2003). Also, Alkaloids may act on the central nervous system and cause paralysis (Roy et al. 2010), which gave nematicidal effects. Important notice should be considered when comparing the efficacy of ethanolic and water extracts; solidago extracts with both solvents were the most toxic on J2. However, Periwinkle extract nematicidal effects were pronounced only in the aqueous extract and reduced greatly in the ethanolic one. Herein, the nematicidal and ovicidal effects of periwinkle extract are basically due to the water-soluble fractions.

Solidago aqueous extract had a higher percentage of compounds known with their nematicidal activity than periwinkle extract; such as terpenoids (Ohri and Pannu 2009), glycosides (Pronar 1983), and piperazines. Actually, for a long time, piperazine derivatives are used as antihelmintic drugs for humans (Shafei et al. 1955).

There is a real need for fractionation of the constituents of the extract to test each compound individually. 
However, one can generalize that the bioactivity against nematodes of each extract follows a multi-site mode of action. This is simply because that there is a large number of compounds in each extract, and these compounds have different functional groups with different modes of action.

Flavonoids, low molecular weight secondary metabolites have diverse functions including defense and auxin transport inhibition, and are implicated in resistance to both sedentary and migratory nematodes (Baldridge et al. 1998). Also, hypersensitive response and accumulation of the phytoalexin glyceollin, a product of isoflavonoids inhibit oxidation, respiration of $M$. incognita in vitro and accumulate adjacent to the head region of soybean cyst nematode in resistant root tissues (Kaplan and Keen 1980).

Phenolic compounds interfere with the energy generation mechanism by uncoupling the oxidative phosphorylation and interfere with glycoprotein of the cell surface of the parasite and cause death (John et al. 2009). Glycosides nematicidal effects are due to their function as a cholinesterase inhibitor that prohibits the normal buildup of nematode (Pronar 1983).

It has been found that prolonging the time of storage of extracts affects their stability and minimizes activity on nematode mortality, which was also influenced by the extract type. Aqueous extracts of periwinkle and solidago could be stored for 12 months without significant loss of nematicidal activity against M. incognita. The boiled extracts of Bidenspilosa could be stored for 12-18 months without loss of nematoxic activity (Taba et al. 2012).

Periwinkle and solidago extracts showed toxic effects on the free-living nematode and rotifers in vitro. Logically it may be lower than that of the synthetic nematicides but plant extracts are still considered xenobiotics and could alter the normal activity of the microfauna in the soil. Storage experiment revealed that bioactive compounds in these extracts were stable only at freezing temperatures, so biodegradation of these extracts in the soil is expected in a short period.

The greenhouse results emphasized the toxicity action of periwinkle and solidago extracts either foliar spray or soil drench treatment under different intervals on $M$. incognita parameters. The negative effects of solidago were more pronounced than periwinkle in most concentrations, method as well as the time of application. The nematicidal phytochemicals represented $90 \%$ of the total phytochemicals recovered from solidago meanwhile, that percentage was $75 \%$ for periwinkle. The nematode reduction outcomes may be due to the toxic contact action to the nematode juveniles and to the small molecular weight phytochemicals, which absorbed by roots easily that raise the plant resistance against nematodes or may have systemic nematicidal action as proven by pre-, with, and post-inoculation applications. That systemic nematicidal action may be attributable to the high ratios of phytochemical components (Archana and Parasad 2014) on other plants with different concentrations. Flavonoids could help in plant resistance against nematodes by affecting chemotaxis towards roots and interfere with functions in nematode reproduction (Chin et al. 2018). They added that the mechanism of these effects is still unknown. This can interpret the decline in reproduction factor and number of galls due to the application of both extracts. The medicinal plant extractions treated as soil drench showed significant reducing effects and nematicidal activity to $M$. incognita criteria (El-Nagdi and Youssef 2013). The described effects on $M$. incognita were achieved by using plant extracts with low concentrations under lab and greenhouse conditions which started with $0.5 \mathrm{~g} / \mathrm{l}$ and did not exceed $2 \mathrm{~g} / \mathrm{l}$ of the dry leaves. Comparing the used concentrations with the chemical nematicides may minimize the coast effectiveness. Solidago and periwinkle might be promising candidates of nematode management tactics.

\section{Conclusion}

Extracts of solidago and periwinkle leaves might be promising sources of phytochemicals that have nematicidal activity.

\section{Abbreviations}

RKN: Root-knot nematode; D.Wt./L: Dry weight/liter; GC/MS/MS: Gas chromatography/mass spectrometry and gas chromatography/tandem mass spectrometry; ANOVA: Analysis of variance; $\mathrm{LC}_{50}$ : Median lethal concentration $\mathrm{LC}_{90}$ : Ninety lethal concentration

\section{Acknowledgements}

Not applicable.

\section{Authors' contributions}

Methodology, H.K. and A.A-R.; formal analysis, S.S. and A.A.; investigation, H.K., A.A-R, and A.A.; resources, H.K. and S.S.; data curation, A.A.; supervision, A.A. and K.K; writing-original draft preparation, H.K, A.A-R., and A.A. writing-review and editing, H.K., S.S., and A.A. All authors have read and agreed to the published version of the manuscript.

\section{Funding}

This study was financed by Taif University Researchers Supporting Project number (TURSP-2020/92), Taif University, Taif, Saudi Arabia. This funder provided most chemicals used in plant extract and experimental bioassay.

Availability of data and materials

All data generated or analyzed in this study are available in this published manuscript.

\section{Declarations}

Ethics approval and consent to participate Not applicable.

Consent for publication

This study does not contain any individual person's data.

Competing interests

The authors declare that they have no competing interests. 


\section{Author details}

'Zoology and Agricultural Nematology Department, Faculty of Agriculture, Cairo University, Giza 12613, Egypt. ${ }^{2}$ Department of Science and Technology, University College-Ranyah, Taif University, B.O. Box 11099, Taif 21944, Saudi Arabia.

Received: 24 February 2021 Accepted: 4 May 2021

Published online: 10 May 2021

\section{References}

Adegbite AA (2003) Comparative effects of Carbofuran and water extract of Chromolaena odorata on growth, yield and food components of root-knot nematode-infested soybean [Glycine max (L.) Merrill]. Ph. D thesis, University of Ibadan, Ibadan

Archana US, Parasad D (2014) Management of Plant-parasitic Nematodes by the Use of botanicals. Ann Plant Protec Sci 10(2):360-364 https://doi.org/10.41 72/2329-955X.1000116

Baldridge GD, O'Neill NR, Samac DA (1998) Alfalfa (Medicago sativa L) resistance to the root- lesion nematode, Pratylenchus penetrans: defense-response gene mRNA and isoflavonoidphytoalexin levels in roots. Plant Mol Biol 38(6):9991010. https://doi.org/10.1023/A:1006182908528

Boneti JIS, Ferraz S (1981) Modificação do método de Hussey \& Barker para extração de ovos de Meloidogyne exigua em cafeeiro. Fitopatol Bras Abst 6: 553

Bridge J (1996) Nematode management in sustainable and subsistence agriculture. Annu Rev Phytopathol 34(1):201-225. https://doi.org/10.1146/a nnurev.phyto.34.1.201

Chin S, Behm CA, Mathesius U (2018) Functions of flavonoids in plant-nematode interactions. Plants 7(85):1-17 https://doi.org/10.3390/plants7040085

Dong L, Li X, Huang L, Gao Y, Zhong L, Yuanyuan Z, Zuo Y (2014) Lauric acid in crown daisy root exudate potently regulates root-knot nematode chemotaxis and disrupts Mi-flp-18 expression to block infection. J Exp Bot 65(1):131-141 https://doi.org/10.1093/jxb/ert356

El-Nagdi WE, Youssef MMA (2013) Comparative efficacy of garlic clove and castor seed aqueous extracts against the root-knot nematode, Meloidogyne incognita infecting tomato plants. J Plant Prot Res 53(3):285-288 https://doi. org/10.2478/jppr-2013-0042

Finney DJ (1971) Probit analysis, 3rd edn. Cambridge Univ. Press, Cambridge, p 333

Hooper DJ, Hallmann J, Subbotin SA (2005) Methods for extraction, processing and detection of plant and soil nematodes. In: Luc M, Sikora RA, Bridge J (eds) Plant parasitic nematodes in subtropical and tropical agriculture. CABI Publishing, Wallingford, pp 53-86

Hussey RS, Barker KR (1973) A comparison method of collecting inocula for Meloidogyne spp. including a new technique. Plant Dis Rep 57(12):1025-1028

John S, Chitra KR, Nambisan B, Mohandas C (2009) Nematicidal action of Cassava cyanogenson root-knot nematode (Meloidogyne incognita). Indian J Nematol 11:57-60

Kaplan DT, Keen NT (1980) Mechanisms conferring plant incompatibility to nematodes. Revue Nematol 3(1):123-134

Manju P, Meena S (2015) Antinemic properties of the botanicals. IJSN 6(2):125134

Neeraj GS, Kumar A, Ram S, Kumar V (2017) Evaluation of nematicidal activity of ethanolic extracts of medicinal plants to Meloidogyne incognita (Kofoid and White) chitwood under lab conditions. Int J Pure App Biosci 5(1):827-831. https://doi.org/10.18782/2320-7051.2525

Ng ZX, Samsuri SN, Yong PH (2020) The antioxidant index and chemometric analysis of tannin, flavonoid, and total phenolic extracted from medicinal plant foods with the solvents of different polarities. J Food Process Preserv 44(9):e14680

Ohri P, Pannu SK (2009) Effect of terpenoids on nematodes: a review. J Environ Res Dev 4:171-177

Oostenbrink M (1966) Major characteristics of the relation between nematodes and plants. Meded Land- bouwhogeschool Wageningen 66:3-46

Pandey A, Tripathi S (2014) Concept of standardization, extraction and pre phytochemical screening strategies for herbal drug. J Pharmacogn Phytochem 2(5):115-119

Pronar OG (1983) Control of nematodes. In: The natural history of nematodes. Library of Congress cataloging in Publication Data by Prentice. Hall, Inc, Engle- wood, pp 289-298
Rocha TL, Soll CB, Boughton BA, Silva TS, Oldach K, Firmino AA, Silva LP, Polez VLP, Pelegrini PB, Bacicb A, Grossi-de-Sa M, Roessner U (2017) Prospection and identification of nematotoxic compounds from Canavalia ensiformis seeds effective in the control of the root knot nematode, Meloidogyne incognita. Biotechnol Res Innov 1(1):87-100 https://doi.org/10.1016/j.biori.201 7.10 .003

Roy H, Chakraborty A, Bhanja S, Nayak BS, Mishra SR, Ellaiah P (2010) Preliminary phytochemical investigation and anthelmintic activity of Acanthospermum hispidum DC. J Pharm Sci Technol 2(5):217-221

Shafei AZ, Nagaty HF, Rifaat MA, Salem S (1955) Piperazine as anthelmintic. Lancet 269:827-829

Sun YP (1950) Toxicity index an improved of comparing the relative toxicity of insecticides. J Econ Entomol 43(1):45-53 https://doi.org/10.1093/jee/43.1.45

Taba S, Ajitomi A, Shimabukuro Y, Yonaha M, Takara A, Nagamatsu Y, Moromizato Z (2012) Nematicidal activity of Bidens pilosa var. radiata boiled extracts on plant-parasitic nematodes and stability of the activity. J Weed Sci Technol 57(1):1-6 https://doi.org/10.3719/weed.57.1

Taniwiryono D, Berg H, Riksen JAG, Rietjens IMCM, Djiwantia SR, Kammenga JE, Murk AJ (2009) Nematicidal activity of plant extracts against the root-knot nematode, Meloidogyne incognita. Open Nat Prod J 2(1):77-85 https://doi. org/10.2174/1874848100902010077

Taylor AA, Dropkin VH, Martin GC (1955) Perineal pattern of root-knot nematodes. Phytopathology 45:26-30

Zaidat SAE, Mouhouche F, Babaali D, Abdessemed N, De Cara M (2020). https:// doi.org/10.1186/s41938-020-00242-z) Hammache M (2020) Nematicidal activity of aqueous and organic extracts of local plants against Meloidogyne incognita (Kofoid and White) Chitwood in Algeria under laboratory and greenhouse conditions. Egypt J Biol Pest Control 30(1):46

\section{Publisher's Note}

Springer Nature remains neutral with regard to jurisdictional claims in published maps and institutional affiliations.

\section{Submit your manuscript to a SpringerOpen ${ }^{\circ}$ journal and benefit from:}

- Convenient online submission

- Rigorous peer review

- Open access: articles freely available online

- High visibility within the field

- Retaining the copyright to your article

Submit your next manuscript at $\boldsymbol{\nabla}$ springeropen.com 